\title{
Evaluation of body weight and visual scores for genetic improvement of Nelore cattle
}

\author{
F. M. Paterno ${ }^{1}$ - M. E. Buzanskas ${ }^{2}$-W. Koury Filho $^{3}$ • R. B. Lôbo ${ }^{4} \cdot$ S. A. Queiroz $^{1}$
}

Received: 16 September 2016/Accepted: 15 December 2016/Published online: 27 December 2016

(C) Springer Science+Business Media Dordrecht 2016

\begin{abstract}
The aims of our study were to estimate genetic parameters for body weight and visual scores and to evaluate their inclusion as selection criteria in the Nelore breeding program in Brazil. The traits studied were the body weight adjusted to 210 (W210) and to 450 (W450) days of age and visual scores for body structure, finishing precocity, and muscling evaluated at weaning $\left(\mathrm{BS}_{\mathrm{W}}, \mathrm{FP}_{\mathrm{W}}\right.$, and $\left.\mathrm{MS}_{\mathrm{W}}\right)$ and yearling $\left(\mathrm{BS}_{\mathrm{Y}}, \mathrm{FP}_{\mathrm{Y}}\right.$, and $\left.\mathrm{MS}_{\mathrm{Y}}\right)$ ages. A total of 33,242, 26,259, 23,075 , and 26,057 observations were considered to analyze $\mathrm{W} 210, \mathrm{~W} 450$, and visual scores at weaning and yearling. The significant $(P<0.05)$ fixed effects for all traits were farm, birth season, birth year, sex, and management group. Singletrait analyses were performed to define the most fitting model to our data using the average information restricted maximum likelihood algorithm, for weaning traits. Subsequently, these models were used in single- and two-trait analyses considering the Bayesian inference algorithm. Two-trait Bayesian analyses resulted in average direct heritability estimates for $\mathrm{BS}_{\mathrm{W}}, \mathrm{FP}_{\mathrm{W}}$, $\mathrm{MS}_{\mathrm{W}}, \mathrm{W} 210, \mathrm{BS}_{\mathrm{Y}}, \mathrm{FP}_{\mathrm{Y}}, \mathrm{MS}_{\mathrm{Y}}$, and $\mathrm{W} 450$ of $0.28,0.30,0.27$, $0.28,0.40,0.44,0.39$, and 0.50 , respectively. Genetic
\end{abstract}

M. E. Buzanskas

marcosbuz@gmail.com

1 Departamento de Zootecnia, Faculdade de Ciências Agrárias e Veterinárias, Universidade Estadual Paulista (UNESP), Jaboticabal, São Paulo 14884-900, Brazil

2 Departamento de Zootecnia, Universidade Federal da Paraíba (UFPB), Areia, Paraíba 58397-000, Brazil

3 Brasil com Z - Zootecnia Tropical, Jaboticabal, São Paulo 14870-260, Brazil

4 Associação Nacional de Criadores e Pesquisadores (ANCP), Ribeirão Preto, São Paulo 14020-230, Brazil correlations varied from 0.40 to 0.96 . Benefits to animal performance can best be achieved by considering body structure, finishing precocity, and muscling as selection criteria in the Nelore breeding programs. The decision to use visual scores measured at weaning should be considered in order to decrease generation interval and assist pre-selecting individuals, expecting carcass improvements in the future progeny.

Keywords Animal breeding $\cdot$ Beef cattle $\cdot$ Bos indicus . Maternal effects

\section{Introduction}

The beef cattle farming in Brazil has invested in genetic improvement of herds in order to achieve higher productivity and attain the consumer market demands on quality and quantity. Therefore, producers are investing in the identification and selection of animals with growth and reproduction precocity as well as with adequate carcass quality (Terakado et al. 2015).

The measurement of body weight traits at standard ages is routinely conducted on the farms, considering that Brazilian producers are paid by carcass weight. Thus, these traits are the most common in the selection indices of breeding programs and they present heritability estimates from moderate to high (Pinheiro et al. 2012; Santana et al. 2013). However, other measures related to body weight could be considered to evaluate the body composition of the animals. Visual scores have been used to identify animals with different body frames with more efficient performance under viable breeding conditions (Gordo et al. 2012).

Attributing visual scores by a trained technician is a lowcost evaluation and can be implemented during routine body 
weight measurements (i.e., at weaning and yearling). The method proposed by Koury Filho et al. (2010) considers the measures of body structure, finishing precocity, and muscling. Previous studies showed that these traits have moderate to high heritability estimates (Faria et al. 2010; Gordo et al. 2012). Thus, the aim of our study was to estimate genetic parameters for body weight and visual scores at weaning and yearling ages and evaluate their inclusion as selection criteria in the Nelore breeding program.

\section{Material and methods}

\section{Animals and data}

Data from 37,826 Nelore cattle born from 2002 to 2014 were analyzed. The animals belonged to farmers who participated in the Nelore Genetic Improvement Program (Nelore Brazil), which is coordinated by the National Breeders' and Researchers' Association (ANCP). The traits studied were the body weight adjusted to 210 (W210) and to 450 (W450) days of age and visual scores for body structure, finishing precocity, and muscling evaluated at weaning $\left(\mathrm{BS}_{\mathrm{W}}, \mathrm{FP}_{\mathrm{W}}\right.$, and $\left.\mathrm{MS}_{\mathrm{W}}\right)$ and yearling $\left(\mathrm{BS}_{\mathrm{Y}}, \mathrm{FP}_{\mathrm{Y}}\right.$, and $\left.\mathrm{MS}_{\mathrm{Y}}\right)$ ages. The relationship matrix included 88,213 animals. On average, the dams and bulls produced 1.9 and 33.7 calves, respectively.

The visual scores were evaluated by trained technicians of ANCP, who first observed the entire management group, separated for males and females, and then evaluated the average profile for each trait by sex, which served as a baseline. Then scores from 1 (lowest expression) to 6 (highest expression), adapted from the method proposed by Koury Filho et al. (2010), were given to the animals. The descriptions of BS, FP, and MS are as follows:

- Body structure (BS): Visually predicts the body area as seen from the side (body length and rib depth). Small animals in the management group receive the score 1, which gradually increases to 6 (large animals).

- Finishing precocity (FP): Strategical points of the animal are evaluated, in which the visual assessment scores of the rib depth in relation to the length of the limbs are carried out. Animals presenting shorter rib depth and longer limbs are frequently less precocious than those with longer rib depth and shorter limbs. Precocious phenotype requires less time for fat deposition, being desired in order to identify possibly earlier animals. Score 1 is related to animals with lower precocity and score 6 to early animals.

- Muscling (MS): MS was assessed by the distribution of muscle mass in the body and the convexity of the muscles in the carcass. Scores 1 to 6 are assigned to animals with muscle mass volume varying from "thinner" to "thicker," respectively.

\section{Genetic analyses}

Analyses performed by means of the least squares method, using the GLM procedure of the SAS software (SAS 9.1, SAS Institute, Cary, NC, USA), aided to define the fixed effects that were considered in the mixed models. Thus, the significant $(P<0.05)$ effects considered for the contemporary groups in all traits were farm, birth season, birth year, sex, and management group. The significant $(P<0.05)$ covariates considered for $\mathrm{BS}_{\mathrm{W}}$, $\mathrm{FP}_{\mathrm{W}}, \mathrm{MS}_{\mathrm{W}}, \mathrm{BS}_{\mathrm{Y}}, \mathrm{FP}_{\mathrm{Y}}$, and $\mathrm{MS}_{\mathrm{Y}}$ were age at evaluation (linear effect) and age of the dam at calving (linear and quadratic effects). For W210 and W450, the significant $(P<0.05)$ covariate was the age of the dam at calving (linear and quadratic effects).

Sires with less than three offspring and contemporary groups with less than three records were removed from the final data file. The UNIVARIATE procedure from SAS (SAS 9.1, SAS Institute, Cary, NC, USA) was used to evaluate the residual normality for each trait, and observations exhibiting a standardized residual 3.5-fold above or below the standard deviation were excluded.

Single-trait analyses were performed to define the most fitting model to our data using the Average Information Restricted Maximum Likelihood algorithm, from Wombat software (Meyer 2007), for weaning traits considering the inclusion of either the maternal genetic and/or the maternal permanent environmental effects. Subsequently, the chosen models were used in single- and two-trait analyses considering the Bayesian inference algorithm present in the thrgibbsf90b software (Tsuruta and Misztal 2006).

The four models studied in single-trait analyses were additive genetic direct and residual effects (model 1, M1); additive genetic direct, maternal permanent environmental, and residual effects (model 2, M2); additive genetic direct, maternal genetic, and residual effects (model 3, M3); and additive genetic direct, maternal genetic, maternal permanent environmental, and residual effects (model 4, M4).

The complete statistical model (M4) is represented by the following:

$y=X \beta+Z a+M m+W p e+e$

where $y$ is the vector of records for each body weight measure, $\beta$ is the vector of fixed effects (contemporary groups and covariates), $a$ is the vector of animal additive genetic direct effects, $m$ is the vector of maternal genetic effects, $p e$ is the vector of maternal permanent environmental effects, and $e$ is the vector of random residuals. $X, Z, M$, and $W$ are the incidence matrices associated with their respective effects for $y$. 
Table 1 Descriptive statistics for body weight at 210 (W210) and 450 (W450) days of age, body structure, finishing precocity, and muscling at weaning $\left(\mathrm{BS}_{\mathrm{W}}, \mathrm{FP}_{\mathrm{W}}\right.$, and $\left.\mathrm{MS}_{\mathrm{W}}\right)$ and yearling $\left(\mathrm{BS}_{\mathrm{Y}}, \mathrm{FP}_{\mathrm{Y}}\right.$, and $\left.\mathrm{MS}_{\mathrm{Y}}\right)$ ages

\begin{tabular}{|c|c|c|c|c|c|c|c|c|c|c|c|}
\hline Traits & $\begin{array}{l}\text { Number of } \\
\text { animals }\end{array}$ & $\begin{array}{l}\text { Number of } \\
\text { sires }\end{array}$ & $\begin{array}{l}\text { Number of } \\
\text { dams }\end{array}$ & $\begin{array}{l}\text { Number of } \\
\text { CG }\end{array}$ & Mean & Mode & Median & $\begin{array}{l}\text { Standard } \\
\text { deviation }\end{array}$ & CV\% & $\begin{array}{l}\text { Minimum } \\
\text { values }\end{array}$ & $\begin{array}{l}\text { Maximum } \\
\text { values }\end{array}$ \\
\hline $\mathrm{BS}_{\mathrm{W}}$ & 23,075 & 574 & 12,339 & 576 & - & 4 & 4 & - & - & 1 & 6 \\
\hline $\mathrm{FP}_{\mathrm{W}}$ & 23,075 & 574 & 12,339 & 576 & - & 4 & 4 & - & - & 1 & 6 \\
\hline $\mathrm{MS}_{\mathrm{W}}$ & 23,074 & 574 & 12,339 & 576 & - & 4 & 4 & - & - & 1 & 6 \\
\hline $\begin{array}{r}\text { W210 } \\
(\mathrm{kg})\end{array}$ & 33,242 & 796 & 17,748 & 1034 & 193.21 & - & - & 27.99 & 14.49 & 91 & 302 \\
\hline $\mathrm{BS}_{\mathrm{Y}}$ & 26,057 & 719 & 15,531 & 547 & - & 4 & 4 & - & - & 1 & 6 \\
\hline $\mathrm{FP}_{\mathrm{Y}}$ & 26,057 & 719 & 15,531 & 547 & - & 4 & 4 & - & - & 1 & 6 \\
\hline $\mathrm{MS}_{\mathrm{Y}}$ & 26,057 & 719 & 15,531 & 547 & - & 3 & 4 & - & - & 1 & 6 \\
\hline $\begin{array}{r}\text { W450 } \\
(\mathrm{kg})\end{array}$ & 26,259 & 709 & 14,864 & 1024 & 285.54 & - & - & 51.34 & 17.98 & 124 & 480 \\
\hline
\end{tabular}

$C G$ contemporary groups, $C V \%$ coefficient of variation

The assumptions for the general model were as follows:

$$
\begin{aligned}
E[y] & =X \beta, \quad E\left[\begin{array}{c}
a \\
m \\
p e \\
e
\end{array}\right]=\left[\begin{array}{l}
0 \\
0 \\
0 \\
0
\end{array}\right], \operatorname{Var}\left[\begin{array}{c}
a \\
m \\
p e \\
e
\end{array}\right] \\
& =\left[\begin{array}{cccc}
A \sigma_{a}^{2} & 0 & 0 & 0 \\
0 & A \sigma_{m}^{2} & 0 & 0 \\
0 & 0 & I \sigma_{p e}^{2} & 0 \\
0 & 0 & 0 & I \sigma_{e}^{2}
\end{array}\right]
\end{aligned}
$$

in which $\sigma_{a}^{2}$ is the additive genetic variance, $\sigma_{m}^{2}$ is the additive maternal genetic variance, $\sigma_{p e}^{2}$ is the maternal permanent environmental variance, $\sigma_{e}^{2}$ is the residual variance, $A$ is the relationship matrix, and $I$ is the identity matrix.

Analyses using average information restricted maximum likelihood (AIREML) considered the animal model and convergence criteria of $10^{-9}$. In these analyses, the likelihood ratio test (LRT) was conducted between the four models in order to test the significance of the inclusion of random effects. After this step, the Bayesian analyses were carried out. For yearling
Table 2 Estimates of genetic parameters for body weight at 210 (W210) days of age, body structure, finishing precocity, and muscling at weaning age $\left(\mathrm{BS}_{\mathrm{W}}\right.$, $\mathrm{FP}_{\mathrm{W}}$, and $\mathrm{MS}_{\mathrm{W}}$ ) considering the average information restricted

\begin{tabular}{|c|c|c|c|c|c|c|}
\hline Traits & Model & $h_{\mathrm{d}}^{2} \pm \mathrm{SE}$ & $h_{\mathrm{m}}^{2} \pm \mathrm{SE}$ & $c^{2} \pm \mathrm{SE}$ & $2 * \log L$ & LRT \\
\hline \multirow[t]{4}{*}{$\mathrm{BS}_{\mathrm{W}}$} & M1 & $0.42 \pm 0.02$ & - & - & -27779.24 & $\mathrm{M} 2-\mathrm{M} 1=207.15^{\mathrm{a}}$ \\
\hline & M2 & $0.21 \pm 0.02$ & - & $0.14 \pm 0.01$ & -27572.09 & $\mathrm{M} 3-\mathrm{M} 1=211.46^{\mathrm{a}}$ \\
\hline & M3 & $0.17 \pm 0.02$ & $0.15 \pm 0.01$ & - & -27567.78 & $\mathrm{M} 4-\mathrm{M} 2=57.87^{\mathrm{a}}$ \\
\hline & M4 & $0.17 \pm 0.02$ & $0.07 \pm 0.01$ & $0.10 \pm 0.01$ & -27514.21 & $\mathrm{M} 4-\mathrm{M} 3=53.57^{\mathrm{a}}$ \\
\hline \multirow[t]{4}{*}{$\mathrm{FP}_{\mathrm{W}}$} & M1 & $0.42 \pm 0.02$ & - & - & -29443.18 & $\mathrm{M} 2-\mathrm{M} 1=133.85^{\circ}$ \\
\hline & M2 & $0.28 \pm 0.02$ & - & $0.11 \pm 0.01$ & -29309.34 & $\mathrm{M} 3-\mathrm{M} 1=161.60^{\circ}$ \\
\hline & M3 & $0.23 \pm 0.02$ & $0.12 \pm 0.01$ & - & -29281.58 & $\mathrm{M} 4-\mathrm{M} 2=59.85^{\mathrm{a}}$ \\
\hline & M4 & $0.23 \pm 0.02$ & $0.06 \pm 0.01$ & $0.07 \pm 0.01$ & -29249.49 & $\mathrm{M} 4-\mathrm{M} 3=32.09^{\mathrm{a}}$ \\
\hline \multirow[t]{4}{*}{$\mathrm{MS}_{\mathrm{W}}$} & M1 & $0.43 \pm 0.02$ & - & - & -29821.91 & $\mathrm{M} 2-\mathrm{M} 1=177.90^{\circ}$ \\
\hline & M2 & $0.26 \pm 0.02$ & - & $0.13 \pm 0.01$ & -29644.01 & $\mathrm{M} 3-\mathrm{M} 1=216.58^{\mathrm{a}}$ \\
\hline & M3 & $0.19 \pm 0.02$ & $0.15 \pm 0.01$ & - & -29605.33 & $\mathrm{M} 4-\mathrm{M} 2=80.49^{\mathrm{a}}$ \\
\hline & M4 & $0.20 \pm 0.02$ & $0.08 \pm 0.01$ & $0.08 \pm 0.01$ & -29563.53 & $\mathrm{M} 4-\mathrm{M} 3=41.80^{\mathrm{a}}$ \\
\hline \multirow[t]{4}{*}{ W210 } & M1 & $0.58 \pm 0.01$ & - & - & -226082.35 & $\mathrm{M} 2-\mathrm{M} 1=825.91^{\circ}$ \\
\hline & M2 & $0.26 \pm 0.02$ & - & $0.23 \pm 0.01$ & -225256.44 & $\mathrm{M} 3-\mathrm{M} 1=837.91^{\circ}$ \\
\hline & M3 & $0.19 \pm 0.02$ & $0.26 \pm 0.01$ & - & -225244.44 & $\mathrm{M} 4-\mathrm{M} 2=218.53^{\circ}$ \\
\hline & M4 & $0.19 \pm 0.02$ & $0.10 \pm 0.01$ & $0.16 \pm 0.01$ & -225037.91 & $\mathrm{M} 4-\mathrm{M} 3=206.53^{\mathrm{a}}$ \\
\hline
\end{tabular}
maximum likelihood algorithm $h^{2}{ }_{d}$ direct heritability estimate, $h^{2}{ }_{m}$ maternal heritability estimate, $c^{2}$ proportion of maternal permanent environmental variance to total variance, $M 1 \sigma_{a}^{2}+\sigma_{e}^{2}, M 2 \sigma_{a}^{2}+\sigma_{m}^{2}+\sigma_{e}^{2}, M 3 \sigma_{a}^{2}+\sigma_{p e}^{2}+\sigma_{e}^{2}, M 4 \sigma_{a}^{2}+\sigma_{m}^{2}+\sigma_{p e}^{2}+\sigma_{e}^{2}$, $\sigma_{a}^{2}$ additive genetic direct variance, $\sigma_{m}^{2}$ maternal genetic variance, $\sigma_{e}^{2}$ residual variance, $\sigma_{p e}^{2}$ maternal permanent environment variance, $2 * \log L$ two times the logarithm of the likelihood, $L R T$ likelihood ratio test, $S E$ standard error

${ }^{\mathrm{a}}$ Significantly different from zero $\left(\mathrm{LRT}<\chi_{(1 \%)}^{2}=6.63\right)$ 
Table 3 Direct heritability estimates $\left(h_{\mathrm{d}}^{2}\right)$ obtained by Bayesian inference in single-trait (diagonal, in italics) and two-trait (off-diagonal) analyses for body weight at 210 (W210) and 450 (W450) days of age, body structure, finishing precocity, and muscling at weaning $\left(\mathrm{BS}_{\mathrm{W}}, \mathrm{FP}_{\mathrm{W}}\right.$, and $\left.\mathrm{MS}_{\mathrm{W}}\right)$ and yearling $\left(\mathrm{BS}_{\mathrm{Y}}, \mathrm{FP}_{\mathrm{Y}}\right.$, and $\left.\mathrm{MS}_{\mathrm{Y}}\right)$ ages

\begin{tabular}{lccccccccc}
\hline Traits & $\mathrm{BS}_{\mathrm{W}}$ & $\mathrm{FP}_{\mathrm{W}}$ & $\mathrm{MS}_{\mathrm{W}}$ & $\mathrm{W} 210$ & $\mathrm{BS}_{\mathrm{Y}}$ & $\mathrm{FP}_{\mathrm{Y}}$ & $\mathrm{MS}_{\mathrm{Y}}$ & $\mathrm{W} 450$ & $h^{2}{ }_{\mathrm{d}}^{\mathrm{b}}$ \\
\hline $\mathrm{BS}_{\mathrm{W}}{ }^{\mathrm{a}}$ & 0.20 & 0.19 & 0.20 & 0.20 & 0.42 & 0.28 & 0.27 & 0.44 & 0.28 \\
$\mathrm{FP}_{\mathrm{W}}{ }^{\mathrm{a}}$ & 0.22 & 0.24 & 0.24 & 0.25 & 0.35 & 0.37 & 0.34 & 0.40 & 0.30 \\
$\mathrm{MS}_{\mathrm{W}}{ }^{\mathrm{a}}$ & 0.20 & 0.21 & 0.21 & 0.22 & 0.32 & 0.32 & 0.31 & 0.40 & 0.27 \\
$\mathrm{~W}_{10}{ }^{\mathrm{a}}$ & 0.20 & 0.21 & 0.21 & 0.20 & 0.39 & 0.29 & 0.29 & 0.48 & 0.28 \\
$\mathrm{BS}_{\mathrm{Y}}{ }^{\mathrm{a}}$ & 0.44 & 0.40 & 0.40 & 0.45 & 0.36 & 0.36 & 0.36 & 0.41 & 0.40 \\
$\mathrm{FP}_{\mathrm{Y}}{ }^{\mathrm{a}}$ & 0.45 & 0.46 & 0.46 & 0.46 & 0.42 & 0.42 & 0.42 & 0.45 & 0.44 \\
$\mathrm{MS}_{\mathrm{Y}}{ }^{\mathrm{a}}$ & 0.39 & 0.40 & 0.40 & 0.41 & 0.37 & 0.37 & 0.36 & 0.40 & 0.39 \\
$\mathrm{~W}_{50}{ }^{\mathrm{a}}$ & 0.53 & 0.51 & 0.52 & 0.53 & 0.49 & 0.48 & 0.48 & 0.48 & 0.50 \\
\hline
\end{tabular}

For $\mathrm{BS}_{\mathrm{W}}, \mathrm{FP}_{\mathrm{W}}, \mathrm{MS}_{\mathrm{W}}$, and $\mathrm{W} 210$, the model containing the additive genetic, maternal genetic, maternal permanent environment, and residual effects was used, while for $\mathrm{BS}_{\mathrm{Y}}, \mathrm{FP}_{\mathrm{Y}}, \mathrm{MS}_{\mathrm{Y}}$, and $\mathrm{W} 450$, the model containing the additive genetic and residual effects was used

${ }^{\text {a }}$ Standard deviations equal to 0.02

${ }^{\mathrm{b}}$ Average direct heritability estimates from two-trait analyses

traits, M1 was considered in all analyses. The visual scores were analyzed by a linear model.

The Bayesian analyses conducted using the thrgibbsf $90 \mathrm{~b}$ software (Tsuruta and Misztal 2006) considered a total of $1,200,000$ Gibbs sampling rounds, a burn-in period of 200,000 iterations, a thinning interval of 200 iterations, and resulted in 5000 samples. The convergence was carried out by the Geweke and Heidelberger and Welch diagnoses. These diagnoses were present in the package boa (Smith 2005), from the R software (R Development Core Team 2015).

Table 4 Maternal heritability estimates $\left(h_{\mathrm{m}}^{2}\right)$ obtained by Bayesian inference in single-trait (diagonal, in italics) and two-trait (off-diagonal) analyses for body weight at 210 (W210) and 450 (W450) days of age, body structure, finishing precocity, and muscling at weaning $\left(\mathrm{BS}_{\mathrm{W}}, \mathrm{FP}_{\mathrm{W}}\right.$, and $\left.\mathrm{MS}_{\mathrm{W}}\right)$ and yearling $\left(\mathrm{BS}_{\mathrm{Y}}, \mathrm{FP}_{\mathrm{Y}}\right.$, and $\left.\mathrm{MS}_{\mathrm{Y}}\right)$ ages

\begin{tabular}{lccccccccc}
\hline Traits & $\mathrm{BS}_{\mathrm{W}}$ & $\mathrm{FP}_{\mathrm{W}}$ & $\mathrm{MS}_{\mathrm{W}}$ & $\mathrm{W} 210$ & $\mathrm{BS}_{\mathrm{Y}}$ & $\mathrm{FP}_{\mathrm{Y}}$ & $\mathrm{MS}_{\mathrm{Y}}$ & $\mathrm{W} 450$ & $h^{2}{ }_{\mathrm{m}}^{\mathrm{c}}$ \\
\hline $\mathrm{BS}_{\mathrm{W}}{ }^{\mathrm{a}}$ & 0.09 & 0.10 & 0.10 & 0.10 & 0.04 & 0.07 & 0.07 & 0.03 & 0.08 \\
$\mathrm{FP}_{\mathrm{W}}{ }^{\mathrm{a}}$ & 0.10 & 0.09 & 0.10 & 0.09 & 0.06 & 0.05 & 0.05 & 0.04 & 0.07 \\
$\mathrm{MS}_{\mathrm{W}}{ }^{\mathrm{a}}$ & 0.12 & 0.12 & 0.11 & 0.11 & 0.09 & 0.07 & 0.07 & 0.05 & 0.09 \\
$\mathrm{~W}_{10} 10^{\mathrm{b}}$ & 0.12 & 0.11 & 0.11 & 0.10 & 0.06 & 0.08 & 0.07 & 0.02 & 0.08 \\
\hline
\end{tabular}

${ }^{\text {a }}$ Standard deviations equal to 0.01

${ }^{\mathrm{b}}$ Standard deviations ranging from 0.004 to 0.01

${ }^{\mathrm{c}}$ Average maternal heritability estimates from two-trait analyses. For $\mathrm{BS}_{\mathrm{W}}, \mathrm{FP}_{\mathrm{W}}, \mathrm{MS}_{\mathrm{W}}$, and $\mathrm{W} 210$, the model containing the additive genetic, maternal genetic, maternal permanent environment, and residual effects was used
Table 5 Proportion of maternal permanent environmental variance to total variance $\left(c^{2}\right)$ obtained by Bayesian inference in single-trait (diagonal, in italics) and two-trait (off-diagonal) analyses for body weight at 210 (W210) and 450 (W450) days of age, body structure, finishing precocity, and muscling at weaning $\left(\mathrm{BS}_{\mathrm{W}}, \mathrm{FP}_{\mathrm{W}}\right.$, and $\left.\mathrm{MS}_{\mathrm{W}}\right)$ and yearling $\left(\mathrm{BS}_{\mathrm{Y}}, \mathrm{FP}_{\mathrm{Y}}\right.$, and $\left.\mathrm{MS}_{\mathrm{Y}}\right)$ ages

\begin{tabular}{lccccccccc}
\hline Traits & $\mathrm{BS}_{\mathrm{W}}$ & $\mathrm{FP}_{\mathrm{W}}$ & $\mathrm{MS}_{\mathrm{W}}$ & $\mathrm{W} 210$ & $\mathrm{BS}_{\mathrm{Y}}$ & $\mathrm{FP}_{\mathrm{Y}}$ & $\mathrm{MS}_{\mathrm{Y}}$ & $\mathrm{W} 450$ & $c^{2 \mathrm{c}}$ \\
\hline $\mathrm{BS}_{\mathrm{W}}{ }^{\mathrm{a}}$ & 0.10 & 0.10 & 0.10 & 0.10 & 0.05 & 0.09 & 0.09 & 0.30 & 0.12 \\
$\mathrm{FP}_{\mathrm{W}}{ }^{\mathrm{a}}$ & 0.08 & 0.07 & 0.07 & 0.07 & 0.05 & 0.06 & 0.07 & 0.03 & 0.06 \\
$\mathrm{MS}_{\mathrm{W}}{ }^{\mathrm{a}}$ & 0.09 & 0.09 & 0.09 & 0.08 & 0.06 & 0.08 & 0.08 & 0.04 & 0.08 \\
$\mathrm{~W}^{2} 10^{\mathrm{b}}$ & 0.09 & 0.15 & 0.15 & 0.16 & 0.09 & 0.13 & 0.13 & 0.05 & 0.12
\end{tabular}

For $\mathrm{BS}_{\mathrm{W}}, \mathrm{FP}_{\mathrm{W}}, \mathrm{MS}_{\mathrm{W}}$, and $\mathrm{W} 210$, the model containing the additive genetic, maternal genetic, maternal permanent environment, and residual effects was used

${ }^{\text {a }}$ Standard deviations equal to 0.01

${ }^{\mathrm{b}}$ Standard deviations ranging from 0.003 to 0.01

${ }^{\mathrm{c}}$ Average proportion of maternal permanent environmental variance to total variance from two-trait analyses

\section{Results and discussion}

The AIREML convergence was achieved for all single-trait analyses (Wombat software). For the Bayesian inference analyses (thrgibbs1 190 software), the estimate of proportion of maternal permanent environmental variance to total variance $\left(c^{2}\right)$ for W210 did not converge in the Geweke criterion. The estimates of direct heritability $\left(h_{\mathrm{d}}^{2}\right)$, maternal heritability $\left(h_{\mathrm{m}}^{2}\right)$, and $c^{2}$ for all other traits obtained in Bayesian singletrait analyses converged in the Geweke and Heidelberger and Welch criteria.

The body weight measures from weaning to yearling age decreased around $21 \%$, while for visual scores, the number of evaluated animals increased around $11 \%$ (Table 1). As some producers only evaluate visual scores at yearling age, a difference in the number of animals evaluated at yearling in relation to weaning was observed. For body weight traits, a higher number of animals were evaluated at weaning. In Brazil, several production systems coexist and some farmers sell their calves after weaning or cull part of the herd at this age (Guidolin et al. 2012), and this affected the number of observations for each trait.

The results for direct heritability, maternal heritability, and proportion of maternal permanent environmental variance to total variance obtained in single-trait analyses for $\mathrm{BS}_{\mathrm{W}}, \mathrm{FP}_{\mathrm{W}}$, $\mathrm{MS}_{\mathrm{W}}$, and $\mathrm{W} 210$ are presented in Table 2. According to the LRT, the best-fit model for the traits measured at weaning was M4. Vargas et al. (2014) reported that maternal effects are of great importance to the calf performance, especially at weaning, and the inclusion of this effect in the genetic evaluation should be considered.

The maternal genetic effect could influence body weight trait up to 390 days of age due to the milking 
Table 6 Genetic (above diagonal) and environmental (below diagonal) correlations obtained by Bayesian inference in two-trait analyses for body weight at 210 (W210) and 450 (W450) days of age, body structure, finishing precocity, and muscling at weaning $\left(\mathrm{BS}_{\mathrm{W}}, \mathrm{FP}_{\mathrm{W}}\right.$, and $\left.\mathrm{MS}_{\mathrm{W}}\right)$ and yearling $\left(\mathrm{BS}_{\mathrm{Y}}, \mathrm{FP}_{\mathrm{Y}}\right.$, and $\left.\mathrm{MS}_{\mathrm{Y}}\right)$ ages

\begin{tabular}{lllllllll}
\hline Traits & $\mathrm{BS}_{\mathrm{W}}$ & $\mathrm{FP}_{\mathrm{W}}$ & $\mathrm{MS}_{\mathrm{W}}$ & $\mathrm{W} 210$ & $\mathrm{BS}_{\mathrm{Y}}$ & $\mathrm{FP}_{\mathrm{Y}}$ & $\mathrm{MS}_{\mathrm{Y}}$ & $\mathrm{W}$ \\
\hline $\mathrm{BS}_{\mathrm{W}}$ & - & $0.40 \pm 0.06$ & $0.46 \pm 0.06$ & $0.86 \pm 0.02$ & $0.96 \pm 0.01$ & $0.59 \pm 0.04$ & $0.60 \pm 0.04$ & $0.91 \pm 0.01$ \\
$\mathrm{FP}_{\mathrm{W}}$ & $0.51 \pm 0.01$ & - & $0.90 \pm 0.01$ & $0.62 \pm 0.04$ & $0.66 \pm 0.03$ & $0.96 \pm 0.01$ & $0.92 \pm 0.02$ & $0.83 \pm 0.02$ \\
$\mathrm{MS}_{\mathrm{W}}$ & $0.56 \pm 0.01$ & $0.75 \pm 0.01$ & - & $0.69 \pm 0.04$ & $0.71 \pm 0.03$ & $0.88 \pm 0.02$ & $0.94 \pm 0.01$ & $0.87 \pm 0.02$ \\
$\mathrm{~W} 210$ & $0.62 \pm 0.01$ & $0.54 \pm 0.01$ & $0.56 \pm 0.01$ & - & $0.93 \pm 0.01$ & $0.74 \pm 0.03$ & $0.80 \pm 0.02$ & $0.96 \pm 0.01$ \\
$\mathrm{BS}_{\mathrm{Y}}$ & $0.33 \pm 0.02$ & $0.19 \pm 0.02$ & $0.23 \pm 0.02$ & $0.39 \pm 0.02$ & - & $0.48 \pm 0.03$ & $0.52 \pm 0.03$ & $0.89 \pm 0.01$ \\
$\mathrm{FP}_{\mathrm{Y}}$ & $0.14 \pm 0.02$ & $0.24 \pm 0.02$ & $0.21 \pm 0.01$ & $0.24 \pm 0.02$ & $0.52 \pm 0.01$ & - & $0.92 \pm 0.01$ & $0.73 \pm 0.01$ \\
$\mathrm{MS}_{\mathrm{Y}}$ & $0.17 \pm 0.02$ & $0.23 \pm 0.02$ & $0.27 \pm 0.01$ & $0.24 \pm 0.02$ & $0.53 \pm 0.01$ & $0.73 \pm 0.01$ & - & $0.77 \pm 0.02$ \\
$\mathrm{~W} 450$ & $0.39 \pm 0.02$ & $0.30 \pm 0.02$ & $0.33 \pm 0.02$ & $0.55 \pm 0.01$ & $0.57 \pm 0.01$ & $0.45 \pm 0.01$ & $0.48 \pm 0.02$ & - \\
\hline
\end{tabular}

For $\mathrm{BS}_{\mathrm{W}}, \mathrm{FP}_{\mathrm{W}}, \mathrm{MS}_{\mathrm{W}}$, and $\mathrm{W} 210$, the model containing the additive genetic, maternal genetic, maternal permanent environment, and residual effects was used, while for $\mathrm{BS}_{\mathrm{Y}}, \mathrm{FP}_{\mathrm{Y}}, \mathrm{MS}_{\mathrm{Y}}$, and $\mathrm{W} 450$, the model containing the additive genetic and residual effects was used

and mothering ability of the cow, as well as the uterine environment during gestation (Albuquerque and Meyer 2001). As such, four models were tested to identify the maternal effects (maternal genetic and maternal permanent environmental random effects) for $\mathrm{BS}_{\mathrm{W}}, \mathrm{FP}_{\mathrm{W}}, \mathrm{MS}_{\mathrm{W}}$, and W210 (Table 2). According to the LRT, the maternal effects tested were all significant, which means that these effects affected the considered traits, being M4 (full model) the most appropriate to evaluate visual scores and body weight at weaning.

The estimates of $h_{\mathrm{d}}^{2}, h_{\mathrm{m}}^{2}$, and $c^{2}$ obtained in singleand two-trait analyses under Bayesian inference are presented in Tables 3, 4, and 5, respectively. Direct heritability estimates $\left(h_{\mathrm{d}}^{2}\right)$ for $\mathrm{BS}_{\mathrm{W}}, \mathrm{FP}_{\mathrm{W}}$, and $\mathrm{MS}_{\mathrm{W}}$ ranged from 0.19 to $0.44,0.22$ to 0.40 , and 0.20 to 0.40 , respectively (Table 3). This variation in $h^{2}$ estimates may be due to the covariance structure between these traits with W450 (Table 4), causing an inflation in the heritability estimate. Higher and lower direct heritability estimates for visual scores at weaning were observed by Faria et al. (2010) and Forni et al. (2007).
The $h^{2}{ }_{\mathrm{d}}$ estimated for visual score traits at yearling age presented lower variations among single- and two-trait analyses. For $\mathrm{BS}_{\mathrm{Y}}, \mathrm{FP}_{\mathrm{Y}}$, and $\mathrm{MS}_{\mathrm{Y}}$, the average $h_{\mathrm{d}}^{2}$ were equal to $0.40,0.44$, and 0.39 . Visual scores evaluated at yearling may respond to the selection process faster and more accurately than those taken at weaning due to the high direct heritability observed and, therefore, should be considered as selection criteria in order to improve the body composition to a desired biotype. Our estimates for $\mathrm{BS}_{\mathrm{Y}}, \mathrm{FP}_{\mathrm{Y}}$, and $\mathrm{MS}_{\mathrm{Y}}$ were in the range observed in the literature (Duitama et al. 2015; Faria et al. 2010; Gordo et al. 2012).

For W210, the direct heritability estimates were in agreement with those obtained by Zuin et al. (2012), Bernardes et al. (2015), and Pires et al. (2016) for the Nelore, Tabapuã, and Canchim breeds. Lopes et al. (2016), Vargas et al. (2014), and Mota et al. (2013) observed $h^{2}$ for W450 in Nelore, Brahman, and Simmental animals of $0.52 \pm 0.02,0.22 \pm 0.06$, and 0.27 , respectively. The average maternal heritability obtained for weaning traits were low (Table 4) and similar to those obtained by Vargas et al. (2014) and Lopes et al. (2016). For $c^{2}$,
Table 7 Phenotypic correlations obtained by Bayesian inference in two-trait analyses for body weight at 210 (W210) and 450 (W450) days of age, body structure, finishing precocity, and muscling at weaning $\left(\mathrm{BS}_{\mathrm{W}}, \mathrm{FP}_{\mathrm{W}}\right.$, and $\left.\mathrm{MS}_{\mathrm{W}}\right)$ and yearling $\left(\mathrm{BS}_{\mathrm{Y}}, \mathrm{FP}_{\mathrm{Y}}\right.$, and $\left.\mathrm{MS}_{\mathrm{Y}}\right)$ ages

\begin{tabular}{llllllll}
\hline Traits & $\mathrm{FP}_{\mathrm{W}}$ & $\mathrm{MS}_{\mathrm{W}}$ & $\mathrm{W} 210$ & $\mathrm{BS}_{\mathrm{Y}}$ & $\mathrm{FP}_{\mathrm{Y}}$ & $\mathrm{MS}_{\mathrm{Y}}$ & $\mathrm{W} 450$ \\
\hline $\mathrm{BS}_{\mathrm{W}}$ & $0.49 \pm 0.01$ & $0.54 \pm 0.01$ & $0.67 \pm 0.01$ & $0.60 \pm 0.01$ & $0.30 \pm 0.01$ & $0.31 \pm 0.01$ & $0.64 \pm 0.01$ \\
$\mathrm{FP}_{\mathrm{W}}$ & - & $0.79 \pm 0.01$ & $0.53 \pm 0.01$ & $0.36 \pm 0.01$ & $0.53 \pm 0.01$ & $0.48 \pm 0.01$ & $0.54 \pm 0.01$ \\
$\mathrm{MS}_{\mathrm{W}}$ & - & - & $0.59 \pm 0.01$ & $0.40 \pm 0.01$ & $0.46 \pm 0.01$ & $0.51 \pm 0.01$ & $0.57 \pm 0.01$ \\
$\mathrm{~W} 210$ & - & - & - & $0.61 \pm 0.01$ & $0.42 \pm 0.01$ & $0.44 \pm 0.01$ & $0.76 \pm 0.01$ \\
$\mathrm{BS}_{\mathrm{Y}}$ & - & - & - & - & $0.50 \pm 0.01$ & $0.52 \pm 0.01$ & $0.71 \pm 0.01$ \\
$\mathrm{FP}_{\mathrm{Y}}$ & - & - & - & - & - & $0.80 \pm 0.01$ & $0.58 \pm 0.01$ \\
$\mathrm{MS}_{\mathrm{Y}}$ & - & - & - & - & - & - & $0.60 \pm 0.01$ \\
\hline
\end{tabular}

For $\mathrm{BS}_{\mathrm{W}}, \mathrm{FP}_{\mathrm{W}}, \mathrm{MS}_{\mathrm{W}}$, and $\mathrm{W} 210$, the model containing the additive genetic, maternal genetic, maternal permanent environment, and residual effects was used, while for $\mathrm{BS}_{\mathrm{Y}}, \mathrm{FP}_{\mathrm{Y}}, \mathrm{MS}_{\mathrm{Y}}$, and $\mathrm{W} 450$, the model containing the additive genetic and residual effects was used 
estimates were equal to 0.12 for $\mathrm{BS}_{\mathrm{W}}, 0.06$ for $\mathrm{FP}_{\mathrm{W}}, 0.08$ for $\mathrm{MS}_{\mathrm{W}}$, and 0.12 for $\mathrm{W} 210$ (Table 5).

The genetic and environmental correlations obtained in two-trait analyses are presented in Table 6 . The results indicated that a substantial proportion of genes of additive action are influencing these traits in the same direction. High genetic correlations for the same trait, but measured at different ages, were observed, indicating that visual score evaluations could be carried out either at weaning or yearling ages. Therefore, selection carried out for animals presenting high visual scores at weaning would aid to achieve gains at later ages as well as decrease generation interval. However, due to the maternal effects that could affect weaning trait estimates, direct responses for these traits could be slower than for yearling traits. Furthermore, the harmonious union of all scores will result in animals of greater productive and reproductive potential. Faria et al. (2010) observed high genetic correlation (above 0.59) between visual score traits measured at weaning and yearling ages, except for the genetic correlation between $\mathrm{BS}_{\mathrm{Y}}$ and $\mathrm{FP}_{\mathrm{Y}}$ $(0.11)$, and $\mathrm{BS}_{\mathrm{Y}}$ and $\mathrm{MS}_{\mathrm{Y}}(0.23)$.

High and positive genetic correlations of W210 and W450 with visual score traits were observed. Therefore, the visual scores are a strong indication of the biotype of the animals considering that higher grades related to the animal size (BS) could result in adequate rates between the depth of ribs and height of limbs (FP) and higher muscling (MS). Thus, genetic gains are expected in W210 and W450 when considering visual score traits for selection. Gordo et al. (2012) and Duitama et al. (2015) observed high genetic correlations of visual scores and body weight traits.

The phenotypic correlations are presented in Table 7. Environmental (Table 6) and phenotypic correlations between the studied traits ranged from low to high magnitudes and were similar to the genetic correlations. The environmental correlations between $\mathrm{MS}_{\mathrm{W}}$ and $\mathrm{FP}_{\mathrm{W}}$ and $\mathrm{MS}_{\mathrm{Y}}$ and $\mathrm{FP}_{\mathrm{Y}}$ were the highest, indicating that the environment provided to animals for improving muscling also interacts with finishing precocity. High phenotypic correlations were observed between $\mathrm{FP}_{\mathrm{W}}$ and $\mathrm{MS}_{\mathrm{W}}, \mathrm{FP}_{\mathrm{Y}}$ and $\mathrm{MS}_{\mathrm{Y}}$, and $\mathrm{W} 210$ and $\mathrm{W} 450$.

In Brazil, the pre-selection process is initiated at weaning age, mainly regarding body weight measures and visual assessment traits. Data collection and animal management are carried out more intensively at yearling age, in which reproductive traits (scrotal circumference and early pregnancy rates), carcass traits (ribeye area, back fat thickness, and rump fat thickness), and feet and legs structure are measured. Therefore, some producers may prefer to select or cull individuals at yearling age. Despite of a great evolution over the generations due to intensive selection, Nelore is still a late breed for growth, fat deposition, and reproduction when compared to taurine animals. The usage of strategies, such as genomics, may aid to identify precocious, productive, and more adapted animals in order to decrease generation interval and increase meat quality and production.

\section{Conclusions}

The genetic parameters estimated for visual scores and body weight traits led us to conclude that benefits to animal performance can best be achieved by considering body structure, finishing precocity, and muscling as selection criteria of Nelore breeding programs. The choice of either weaning or yearling ages to evaluate and select animals according to visual scores will depend on the management of the farms because genetic correlations among these traits at the studied ages are high. The decision of using visual scores measured at weaning could be considered in order to decrease generation interval and assist pre-selecting individuals, expecting carcass improvements in the future progeny.

Acknowledgements The authors wish to thank the National Breeders' and Researchers' Association (Associação Nacional de Criadores e Pesquisadores; ANCP) for providing the data used in this study. F. M. Paterno would like to acknowledge CAPES ("Coordenação de Aperfeiçoamento de Pessoal de Nível Superior") for the grant received. S. A. Queiroz and R. B. Lôbo were supported by a fellowship from the National Council of Technological and Scientific Development (CNPq).

\section{Compliance with ethical standards}

Conflict of interest The authors declare that they have no conflict of interest.

\section{References}

Albuquerque, L.G., Meyer, K., 2001. Estimates of direct and maternal genetic effects for weights from birth to 600 days of age in Nelore cattle. Journal of Animal Breeding and Genetics 118, 83-92. doi:10.1046/j.1439-0388.2001.00279.x

Bernardes, P.A., Grossi, D.A., Savegnago, R.P., Buzanskas, M.E., Urbinati, I., Bezerra, L.A.F., Lôbo, R.B., Munari, D.P., 2015. Estimates of genetic parameters and genetic trends for reproductive traits and weaning weight in Tabapuã cattle. Journal of Animal Science 93, 5175-5185. doi:10.2527/jas2015-9212

Duitama, L.O., Fonseca, R., Bertipaglia, T., Machado, C.H., Soares Filho, C. V, 2015. Estimação de parâmetros genéticos para escores visuais e características de desenvolvimento ponderal na raça Nelore. Arquivo Brasileiro de Medicina Veterinaria e Zootecnia 67, 1111-1118.

Faria, C.U., Pires, B.C., Vozzi, A.P., Magnabosco, C.U., Koury Filho, W., Viu, M.A.O., Oliveira, H.N., Lôbo, R.B., 2010. Genetic correlations between categorical morphological traits in Nelore cattle by applying Bayesian analysis under a threshold animal model. Journal of Animal Breeding and Genetics 127, 377-384. doi:10.1111/j.1439-0388.2010.00860.x

Forni, S., Federici, J.F., Albuquerque, L.G., 2007. Tendências genéticas para escores visuais de conformação, precocidade e musculatura à 
desmama de bovinos Nelore. Revista Brasileira de Zootecnia 36, 572-577. doi:10.1590/S1516-35982007000300008

Gordo, D.G.M., Baldi, F., Lôbo, R.B., Filho, W.K., Sainz, R.D., Albuquerque, L.G., 2012. Genetic association between body composition measured by ultrasound and visual scores in Brazilian Nelore cattle. Journal of Animal Science 90, 4223-4229. doi:10.2527/jas.2011-3935

Guidolin, D.G.F., Buzanskas, M.E., Ramos, S.B., Venturini, G.C., Paz, C.C.P., Munari, D.P., Oliveira, J.A., 2012. Genotype environment interaction for post-weaning traits in Nellore beef cattle. Animal Production Science 52, 975-980. doi:http:// dx.doi.org/10.1071/AN11037

Koury Filho, W., Albuquerque, L.G., Forni, S., Silva, J.A.I.V., Yokoo, M.J., Alencar, M.M., 2010. Estimativas de parâmetros genéticos para os escores visuais e suas associações com peso corporal em bovinos de corte. Revista Brasileira de Zootecnia 39, 1015-1022. doi:10.1590/S1516-35982010000500011

Lopes, F.B., Da Silva, M.C., Magnabosco, C.U., Narciso, M.G., Sainz, R.D., 2016. Selection Indices and Multivariate Analysis Show Similar Results in the Evaluation of Growth and Carcass Traits in Beef Cattle. PLoS ONE 11, 1-22. doi:10.1371/journal.pone. 0147180

Meyer, K., 2007. WOMBAT: a tool for mixed model analyses in quantitative genetics by restricted maximum likelihood (REML). Journal of Zhejiang University. Science B 8, 815-21. doi:10.1631/ jzus.2007.B0815

Mota, R.R., Lopes, P.S., Marques, L.F.A., Silva, L.P., Resende, M.D.V., Torres, R. de A., 2013. The influence of animals from embryo transfer on the genetic evaluation of growth in Simmental beef cattle by using multi-trait models. Genetics and Molecular Biology 36, 4349. doi:10.1590/S1415-47572013005000008

Pinheiro, T.R., Mercadante, M.E.Z., de Albuquerque, L.G., Martins Bonilha, S.F., Morato Monteiro, F., 2012. Selection for higher body weight in Nelore cattle is effective in achieving an increase of longissimus muscle area without reducing subcutaneous fat thickness. Revista Brasileira de Zootecnia 41, 1426 1432. doi:10.1590/S1516-35982012000600016

Pires, B.C., Tholon, P., Buzanskas, M.E., Sbardella, A.P., Rosa, J.O., Silva, L.O.C., Torres Júnior, R.A.A., Munari, D.P., Alencar, M.M., 2016. Genetic analyses on body weight, reproductive, and carcass traits in composite beef cattle. Animal Production Science doi: 10.1071/AN15458.

R Development Core Team, 2015. R: A language and environment for statistical computing. R Foundation for Statistical Computing.

Santana, J.L., Eler, J.P., Cucco, D.C., Bignardi, A.B., Ferraz, J.B.S., 2013. Genetic associations between hip height, body conformation scores, and pregnancy probability at 14 months in Nelore cattle. Livestock Science 154, 13-18. doi:10.1016/j.livsci.2013.02.018

Smith, B.J., 2005. Bayesian Output Analysis program (BOA) version 1.1 user's manual.

Terakado, A.P.N., Boligon, A.A., Baldi, F., Silva, J.A.I.I. V, Albuquerque, L.G., 2015. Genetic associations between scrotal circumference and female reproductive traits in Nelore cattle. Journal of Animal Science 93, 2706-2713. doi:10.2527/jas2014-8817

Tsuruta, S., Misztal, I., 2006. THRGIBBS1F90 for estimation of variance components with threshold-linear model, in: 8th World Congress on Genetics Applied to Livestock Production. Belo Horizonte, MG, Brasil.

Vargas, G., Buzanskas, M.E., Guidolin, D.G.F., Grossi, D.A., Bonifácio, A.S., Lôbo, R.B., Fonseca, R., Oliveira, J.A., Munari, D.P., 2014. Genetic parameter estimation for pre- and post-weaning traits in Brahman cattle in Brazil. Tropical Animal Health and Production 46, 1271-1278. doi:10.1007/s11250-014-0640-3

Zuin, R.G., Buzanskas, M.E., Caetano, S.L., Venturini, G.C., Guidolin, D.G.F., Grossi, D.A., Chud, T.C.S., Paz, C.C.P., Lôbo, R.B., Munari, D.P., 2012. Genetic analysis on growth and carcass traits in Nelore cattle. Meat Science 91, 352-357. doi:10.1016/j.meatsci.2012.02.018 